\title{
Comparison of hexachlorophane and chlorhexidine powders in prevention of neonatal infection
}

\author{
V G ALDER, D BURMAN, R A SIMPSON, J FYSH, AND W A GILLESPIE \\ Department of Paediatrics and Department of Microbiology, Bristol Maternity Hospital, Bristol
}

SUMMARY The protective effect of treating the skin of newborn infants with powders containing $1 \%$ chlorhexidine or $0.33 \%$ hexachlorophane was compared. Each was equally effective in preventing colonisation and infection by Staphylococcus aureus. In contrast, the skin became profusely colonised by coagulase-negative staphylococci, irrespective of the powder used. Venous blood concentrations of chlorhexidine were low or undetectable in the few infants whose blood was analysed.

The value of topical chemoprophylaxis with hexachlorophane against staphylococcal colonisation and infection in the newborn is well known. ${ }^{1-4}$ The fact that some hexachlorophane is absorbed through the skin $^{5-7}$ led to a withdrawal of hexachlorophane prophylaxis in many hospitals. This withdrawal was often followed by a resurgence of staphylococcal sepsis, thus confirming the value of the chemoprophylaxis. ${ }^{8-13}$

Toxic effects have been caused by absorption of hexachlorophane but only if used in excessive quantities $^{\mathbf{1 4}}$ or if applied to skin that had been damaged by burns or disease ${ }^{415}$. No side effects have been reported in more then 200000 infants since a talcum powder containing $0 \cdot 33 \%$ hexachlorophane was introduced in Bristol 20 years ago, ${ }^{1}$ nor have side effects been reported in the many infants so treated elsewhere. The blood concentration of hexachlorophane in powder-treated infants is very low, greatly below the level found to be toxic in animals. ${ }^{716}$ Similarly, Plueckhahn et al. ${ }^{17}$ failed to find evidence of damage in very large numbers of infants treated with a hexachlorophane emulsion. On this evidence it would be unwise to stop using hexachlorophane as it gives considerable protection against staphylococcal infection, until an equally effective alternative can be found that is still safer.

\footnotetext{
Bristol Royal Hospital for Sick Children

D BURMAN, consultant paediatrician

J FYSH, Department of Child Health lecturer

Department of Microbiology, Bristol Maternity Hospital

V G ALDER, microbiologist (retired)

R A SIMPSON, senior microbiologist

Trinity College, Dublin

W A GILLESPIE, visiting professor of clinical microbiology
}

\section{Materials and methods}

Infants of at least 37 weeks' gestation and born by vaginal delivery were randomly selected from two lying-in wards of this hospital. All infants were white, of normal birthweights, and remained in the ward for at least 7 days. At birth, the cord was cut at $4 \mathrm{~cm}$ from the skin, ligated with a rubber band, and sprayed with a chlorhexidine preparation (Hibispray No. 1, ICI Ltd). The management of all infants was identical, except for the disinfectant powder used. One group was treated with a talcum powder containing $1 \%$ chlorhexidine (Hibitane, ICI Ltd) and the other with $0.33 \%$ hexachlorophane powder (Ster-zac, Hough, Hoseason and Co. Ltd) already in routine use in this hospital. Both contain $3 \%$ zinc oxide. There were no differences in gestational ages, sex, duration of labour, or birthweights of infants in either group. There was no untreated group of babies as it was not considered justifiable to withhold antistaphylococcal prophylaxis. Each infant was dusted liberally with powder all over the trunk, once daily; in addition the umbilical and perineal areas were powdered at each napkin change after wiping the umbilical cord with alcohol.

Swabs were taken from the umbilicus, perineum, nose, and axillae on the day of birth and on two days subsequently - on day 3,5 , or 7 . These were placed immediately in Stuart's transport medium to which was added disinfectant neutralisers $(2 \%$ Tween 80 and $0.3 \%$ Azoletcin). Swabs were inoculated on to blood agar containing $10 \%$ neutraliser, and on to MacConkey's agar and Sabouraud's agar using a serial dilution technique. 
Plates were incubated aerobically for 48 hours at $37^{\circ} \mathrm{C}$.

Clinical signs of infection were recorded, particularly umbilical or eye infections, and septic lesions of the skin or paronychiae. Swabs from all lesions were cultured. Skin reactions other than infections, such as erythema and oedema, were also noted.

Heparinised venous blood samples were taken from each infant when venous blood was required for other clinical investigations. Venepuncture was not justifiable for experimental purposes only; capillary blood samples were not taken since contamination with chlorhexidine on the skin could not have been excluded. The blood samples were stored at $-20^{\circ} \mathrm{C}$ and sent to the Huntingdon Research Centre, Cambridgeshire, for estimation of chlorhexidine by gas-liquid chromatography. ${ }^{18}$

\section{Results}

A total of 189 infants entered the trial but 15 who left hospital before the 7th day were withdrawn. Of those remaining, 87 were treated with hexachlorophane and 87 with chlorhexidine powder.

The aerobic microbial flora of nose, axillae, perineum, and umbilicus is shown in Table 1. $S$. aureus was rarely isolated and there was no difference between the two groups in colonisation by this organism. $S$. aureus colonisation of the nose was usually greater than at other sites and increased with age (Fig. 1). Only 3 proved staphylococcal infections, paronychiae, or eye infections were found in each group.

However, colonisation by coagulase-negative staphylococci was heavy, $70-90 \%$ for all sites from the day of birth, irrespective of the powder (Fig. 1). Other organisms that were isolated are shown in Table 1 . The only difference between the effects of the two treatments was in the lower colonisation by Escherichia coli of the umbilicus and perineum in the chlorhexidine-treated group (Fig. 2). However, no infection was caused by any organism other than S. aureus.

The incidence of skin reactions was very low in both groups. One infant in the chlorhexidinetreated group developed a slight transient erythema and 6 infants in each group had skin reactions unrelated to the powders - such as napkin rash and neonatal urticaria.

The separation time of the umbilical cord did not significantly differ between the chlorhexidine- and hexachlorophane-treated groups (Table 2).

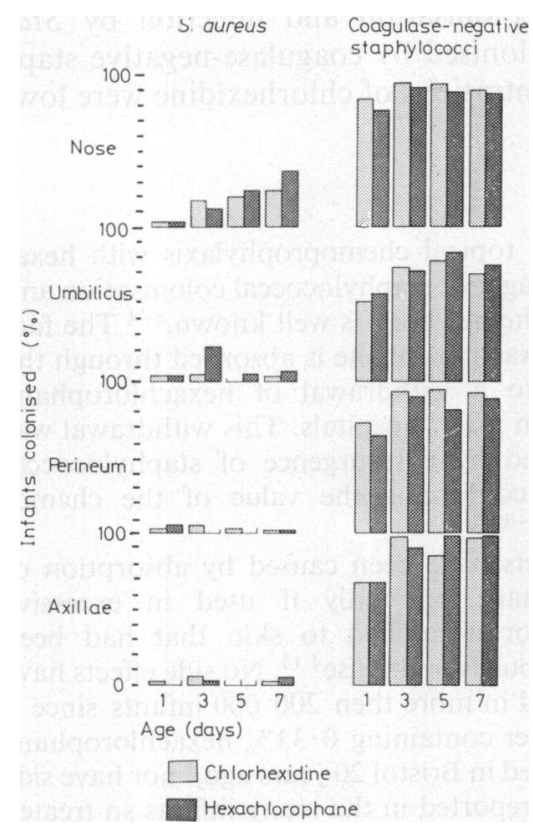

Fig. 1 Colonisation of infants by Staphylococcus aureus and coagulase-negative staphylococci.

Table 1 Microbial flora: percentage of infants colonised at any sampling time during the study

\begin{tabular}{|c|c|c|c|c|c|c|c|c|}
\hline \multirow[t]{3}{*}{ Organism } & \multicolumn{8}{|c|}{ Percentage of infants colonised } \\
\hline & \multicolumn{2}{|l|}{ Nose } & \multicolumn{2}{|c|}{ Umbilicus } & \multicolumn{2}{|l|}{ Perineum } & \multicolumn{2}{|l|}{ Axillae } \\
\hline & $\begin{array}{l}\text { Chlor- } \\
\text { hexidine }\end{array}$ & $\begin{array}{l}\text { Hexachloro- } \\
\text { phane }\end{array}$ & $\begin{array}{l}\text { Chlor- } \\
\text { hexidine }\end{array}$ & $\begin{array}{l}\text { Hexachloro- } \\
\text { phane }\end{array}$ & $\begin{array}{l}\text { Chlor- } \\
\text { hexidine }\end{array}$ & $\begin{array}{l}\text { Hexachloro- } \\
\text { phane }\end{array}$ & $\begin{array}{l}\text { Chlor- } \\
\text { hexidine }\end{array}$ & $\begin{array}{l}\text { Hexachloro- } \\
\text { phane }\end{array}$ \\
\hline Staphylococcus aureus & $21 \cdot 2$ & $34 \cdot 0$ & $2 \cdot 4$ & $22 \cdot 2$ & $4 \cdot 8$ & $5 \cdot 5$ & $4 \cdot 8$ & $4 \cdot 6$ \\
\hline $\begin{array}{l}\text { Coagulase-negative } \\
\text { staphylococci } \\
\text { Escherichia coli }\end{array}$ & $\begin{array}{l}92 \cdot 0 \\
24 \cdot 0\end{array}$ & $\begin{array}{l}87.0 \\
19 \cdot 2\end{array}$ & $\begin{array}{l}77 \cdot 5 \\
42 \cdot 0\end{array}$ & $\begin{array}{l}83 \cdot 0 \\
56 \cdot 0\end{array}$ & $\begin{array}{l}92 \cdot 0 \\
62 \cdot 5\end{array}$ & $\begin{array}{l}88 \cdot 0 \\
75 \cdot 0\end{array}$ & $\begin{array}{l}97 \cdot 5 \\
25 \cdot 0\end{array}$ & $\begin{array}{l}98 \cdot 0 \\
21 \cdot 8\end{array}$ \\
\hline $\begin{array}{l}\text { Other Gram-negatives } \\
\text { Streptococcus faecal is } \\
\text { Candida albicans }\end{array}$ & $\begin{array}{r}5 \cdot 4 \\
22 \cdot 6 \\
0\end{array}$ & $\begin{array}{r}2 \cdot 0 \\
13 \cdot 8 \\
1 \cdot 2\end{array}$ & $\begin{array}{r}9 \cdot 4 \\
12 \cdot 3 \\
4 \cdot 9\end{array}$ & $\begin{array}{l}10 \cdot 1 \\
11 \cdot 7 \\
2 \cdot 0\end{array}$ & $\begin{array}{r}12 \cdot 0 \\
15 \cdot 5 \\
4 \cdot 7\end{array}$ & $\begin{array}{c}18 \cdot 2 \\
20 \cdot 8 \\
0\end{array}$ & $\begin{array}{r}5 \cdot 4 \\
18 \cdot 8 \\
4 \cdot 6\end{array}$ & $\begin{array}{r}4 \cdot 0 \\
16 \cdot 6 \\
5 \cdot 8\end{array}$ \\
\hline Others & $1 \cdot 2$ & 0 & $2 \cdot 4$ & 0 & 0 & 0 & $1 \cdot 2$ & 0 \\
\hline
\end{tabular}




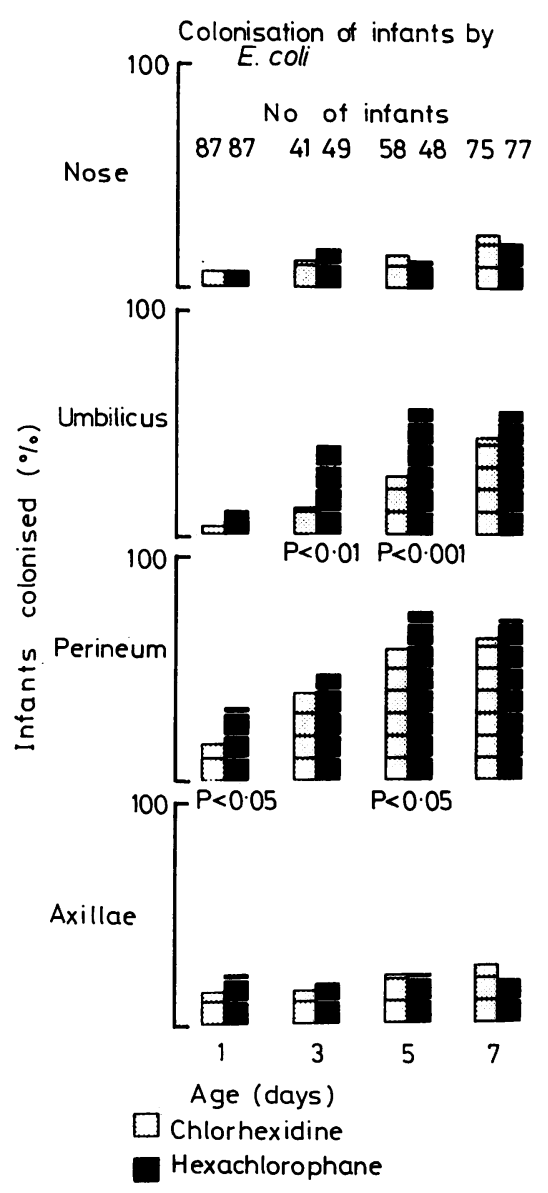

Fig. 2 Colonisation of infants by Escherichia coli.

Table 2 Effects of dusting powder on dates of separation of umbilical cord

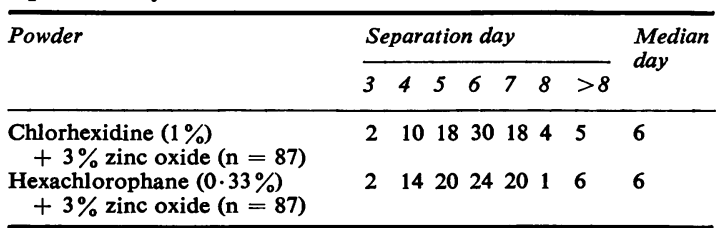

The concentration of chlorhexidine was determined in the blood of 12 infants (Table 3). The level was slightly raised above the limit of detection of the assay method in two (Cases 2 and 12). One of these was in the hexachlorophane-treated group, and it may be significant that his mother was the only one to have had chlorhexidine solution instilled into her bladder before delivery. Hibitane cream is used for
Table 3 Blood chlorhexidine concentrations in infants treated with hexachlorophane or chlorhexidine powder

\begin{tabular}{lcl}
\hline Case & Age (days) & $\begin{array}{l}\text { Blood-chlorhexidine } \\
(\mathrm{mg} / \mathrm{l})\end{array}$ \\
\hline Hexachlorophane & 5 & None detected \\
1 & 5 & $0 \cdot 146^{*}$ \\
2 & 6 & 0.062 \\
3 & 9 & $0 \cdot 047$ \\
4 & 11 & 0.053 \\
5 & 13 & \\
Chlorhexidine & & None detected \\
6 & 3 & 0.032 \\
7 & 6 & 0.017 \\
8 & 6 & 0.034 \\
9 & 6 & None detected \\
10 & 13 & 0.019 \\
11 & 7 & None detected \\
12 & 7 & $0.098^{*}$ \\
\hline
\end{tabular}

*Values significantly different from the background peak heights at $95 \%$ confidence level.

vaginal examinations and the mothers of the two infants with significant chlorhexidine levels had had more examinations than the others.

\section{Discussion}

The use of chlorhexidine or hexachlorophane dusting powder in this study was associated with equally low levels of colonisation and infection by $S$. aureus. In contrast, colonisation of all sites by coagulase-negative staphylococci was strikingly high from the first day of life, irrespective of the disinfectant. This consistent and tenacious colonisation may represent a protective role of the normal skin flora. The only significant differences in bacteriological findings between the two powders was the lower colonisation of the umbilicus by $E$. coli in the chlorhexidine-treated group. Gillespie and colleagues observed delayed umbilical separation time using $0.2 \%$ chlorhexidine in talcum without zinc oxide, ${ }^{19}$ but in the present study we observed no difference between infants treated with chlorhexidine and hexachlorophane powders, both of which contain $3 \%$ zinc oxide. The zinc oxide, with its astringent properties, is probably more important than the disinfectant in reducing cord separation time. ${ }^{20}$

Plueckhahn et al. ${ }^{21}$ expressed concern that the widespread use of $4 \%$ chlorhexidine gluconate would increase the incidence of species of Pseudomonas and Proteus with associated problems of cross infection. However, using a lower concentration of chlorhexidine $(1 \%)$ we found no increase in colonisation by these organisms.

The very low blood levels found in the few infants from whom samples were obtained are in line with the results of Cowen et al. ${ }^{22}$ who studied percutaneous 
absorption in infants bathed with chlorhexidine solution. Case et al. ${ }^{23}$ failed to demonstrate percutaneous absorption from handwashing in $5 \%$ aqueous chlorhexidine solution. Chow et al. $^{24}$ in studies on rats found that less chlorhexidine was absorbed than hexachlorophane under similar conditions.

Even when chlorhexidine is absorbed, its toxicity appears to be low. The $\mathrm{LD}_{50}$ values for chlorhexidine gluconate administered to laboratory animals by oral, subcutaneous, or intravenous routes are very high. ${ }^{25}$ There is a lack of information on toxic effects caused by chlorhexidine in man, and we can find no evidence of systemic toxicity from topical use.

We believe that a topical disinfectant should be used to prevent staphylococcal infection of infants in maternity hospitals. Doctors who prefer to use the disinfectant in powder rather than in liquid form may choose either $1 \%$ chlorhexidine or $0.3 \%$ hexachlorophane in presterilised talcum powder and apply it to the whole body as well as to the umbilicus. The choice will depend on the risks of toxic side effects. Hexachlorophane powder has been consistently effective for more than 20 years and has caused no harm when correctly used. Blood levels in mature infants after $\mathbf{8}$ days' treatment were well below presumed toxic levels based on animal experiments. ${ }^{16}{ }^{20}$ Plueckhahn et al. ${ }^{17}$ found similarly low blood levels in infants treated with hexachlorophane either as $0.75 \%$ emulsion or $0.5 \%$ in powder. However, there have been serious consequences when hexachlorophane was grossly misused or wrongly formulated. 41415

Chlorhexidine was as effective as hexachlorophane and since evidence suggests that it has a wider margin of safety than hexachlorophane, many will probably prefer it. Chlorhexidine powder should soon be available commercially for use by those who prefer to avoid hexachlorophane.

We thank Mr J L Honigman of the Medical Department, and Miss E A Laws (Statistics), ICI Limited, Pharmaceutical Division, for assistance and for supplies of Hibitane powder, and the nursing staff of the Bristol Maternity Hospital, particularly Sister M E Knight, for co-operation.

\section{References}

1 Gillespie W A, Simpson K, Tozer R C. Staphylococcal infection in a maternity hospital. Lancet $1958 ; 2$ : 1075-80.

2 Simpson K, Tozer R C, Gillespie W A. Prevention of staphylococcal sepsis in a maternity hospital by means of hexachlorophane. $\mathrm{Br} \mathrm{Med} J$ 1960; i: 315-7.

3 Cornes B D, Crowther S T, Eades S M. Control of staphylococcal infection in a maternity hospital. $\mathrm{Br}$ Med $J$ 1960; i: 1927-9.

4 Plueckhahn V D. Infant antiseptic skin care and hexachlorophene. Med J Aust 1973; 1 : 93-100.

5 Curley A, Hawk R E, Kimbrough R D, Nathenson G,
Finberg L. Dermal absorption of hexachlorophane in infants. Lancet $1971 ; 2: 296-7$.

- Kopelman A E. Cutaneous absorption of hexachlorophene in low-birthweight infants. $J$ Pediatr 1973; 82: 972-5.

7 Gillespie W A, Corner B D, Burman D, Alder V G. Antimicrobial applications for prophylaxis in the newborn: hexachlorophane. In: Williams $J$ D, Geddes A M, eds. Chemotherapy. Vol. 3. New York: Plenum, 1976: 361-6.

8 Ayliffe G A J, Brightwell K M, Ball P M, Derrington M M. Letter: Staphylococcal infection in cervical glands of infants. Lancet 1972; 2: 479-80.

9 Dewar J, Porter I A, Smylie H G. Letter: Staphylococcal infection in cervical glands of infants. Lancet 1972;2: 712.

10 Campbell G M A, Pitkewicz J S. The incidence of infections in nurseries since the discontinuation of hexachlorophene bathing. Pediatrics $1973 ; 51$ : 360-7.

11 Dixon R E, Kaslow R A, Mallison G F, Bennett J V. Staphylococcal disease outbreaks in hospital nurseries in the United States-December 1971 through March 1972. Pediatrics 1973; 51 : 413-6.

12 Scopes J W, Eykyn S, Phillips I. Letter: Staphylococcal infection in the newborn. Lancet 1974; 2 : 1392.

13 De Souza S W, Lewis D M, Allen L, Thomason F. Letter: Hexachlorophane dusting-powder for newborn infants. Lancet 1975; 1 : 860-1.

14 Goutières F, Aicardi J. Accidental percutaneous hexachlorophane intoxication in children. Br Med J 1977; ii: $663-5$.

15 Shuman R M, Leech R W, Alvard E C, Jr. Neurotoxicity of hexachlorophene in the human. I. A clinicopathologic study of 248 children. Pediatrics $1974 ; 54: 689-95$.

16 Alder V G, Burman D, Corner B D, Gillespie W A. Letter : Absorption of hexachlorophane from infants' skin. Lancet 1972; 2: 384-5.

17 Plueckhahn V D, Ballard B A, Banks J A, Collins R B, Flett $P$ T. Hexachlorophene preparations in infant antiseptic skin care: benefits, risks, and the future. Med J Aust 1978; 2: 555-60.

18 Holmes B F. A note on Hibitane assay with final iodination. In: Read E, ed. Methodological surveys in biochemistry. Chichester: Ellis Horwood, 1978: 7, 328-30.

19 Gillespie W A, Corner B D, Burman D, Alder V G. Absorption of hexachlorophane from dusting powder on newborn infants' skin. J Hyg (Camb) 1974; 73: 311-5.

20 George $R$ H. The effect of antimicrobial agents on the umbilical cord. In: Williams $\mathbf{J} \mathbf{D}$, Geddes $\mathbf{A} \mathbf{M}$, eds. Chemotherapy. Vol. 3. New York: Plenum, 1976: 415-9.

21 Plueckhahn V D, Collins R B, Banks J. Letter: Hexachlorophene emulsions and antiseptic skin care of newborn infants. Med J Aust 1976; 2: 427.

22 Cowen J, Ellis S H, McAinsh J. Absorption of chlorhexidine from the intact skin of newborn infants. Arch Dis Child 1979; 54: 379-83.

23 Case D E, McAinsh J, Rushton A, Winrow M J. Chlorhexidine: attempts to detect percutaneous absorption in man. In: Williams J D, Geddes A M, eds. Chemotherapy. Vol. 3. New York: Plenum, 1976: 367-74.

24 Chow C P, Buttar H S, Downie P H. Percutaneous absorption of chlorhexidine in rats. Toxicol Lett 1978; 1 : 213-6.

25 Imperial Chemical Industries Limited. ICI antiseptics in practice. London: ICI Pharmaceuticals Division, 1978.

Correspondence to Dr R A Simpson, Department of Microbiology, Bristol Maternity Hospital, Southwell Street, Bristol BS2 8EG.

Received 10 May 1979 